\title{
escutando os adultos sobre proteção da infância e crianças em situação de rua no brasil urbano
}

\author{
suzana santos libardi ${ }^{1}$ \\ universidade federal de alagoas - brasil \\ marit ursin ${ }^{2}$ \\ centro norueguês de pesquisas sobre a infância - noruega
}

resumo

Esse trabalho se localiza na área dos estudos da infância, que concebe a criança como sujeito ativo na sociedade e que é, entre outros fatores, marcado pela sua posição geracional perante outras gerações. Nessa oportunidade, refletimos sobre como são percebidas as crianças brasileiras que vivem no espaço urbano e em um contexto de adversidades muito específico: a rua. O objetivo foi conhecer de que forma os adultos percebem as crianças que estão em situação de rua, e como veem o dever de proteção da infância aplicado a essas crianças. Para isso, apresentamos os resultados de duas pesquisas qualitativas, realizadas separadamente pelas autoras, em três cidades diferentes do Brasil, das regiões Nordeste e Sudeste, contando com o total de 77 adultos. Eles participaram por meio de entrevistas individuais ou em grupo. Os registros dos trabalhos de campo foram analisados e geraram categorias que contemplam a questão de quem é a responsabilidade sobre crianças em situação de rua, e a proteção das infâncias marginalizadas. Baseado no trabalho empírico das duas pesquisas, percebemos que os adultos diferenciaram bastante as crianças em situação de rua das outras crianças que não fazem da rua a sua morada. Os participantes elegeram o Estado como o maior responsável pelas crianças em situação de rua. Para essa infância marginalizada, parte dos adultos elencou instituições estatais como as únicas responsáveis por prover algum trato às crianças em situação de rua; o qual não necessariamente se configurou como uma medida de proteção. A responsabilização e a punição foram mais evocadas pelos adultos do que a proteção. Como conclusão, vimos que os adultos não se sentiram convocados a proteger infâncias marginalizadas, por isso pensaram prioritariamente em sua própria proteção e beiraram a negligência para com essas crianças. O reconhecimento aos "pivetes" foi dado somente por vias negativas, pois a criança em situação de rua foi vista por alguns como um mal que age e sabe por que age sendo este o único momento no qual essas crianças foram vistas de forma ativa.

palavras-chave: crianças em situação de rua; proteção da infância; infância.

\section{listening to adults about childhood protection and children in homeless situation in urban brazil}

abstract

This work is situated in the field of childhood studies, which conceives the child as an active subject in society and who is, among other factors, marked by its generational position in front of other generations. In this opportunity, we reflect about how Brazilian kids who live in the urban space and in a very specific adversity context (the streets) are perceived. The objective was to understand how adults perceive those children in homeless situation, and how do they face the duty of childhood protection once it is applied to those specific children. In order to do this, we present the results of two qualitative researches, separately

\footnotetext{
${ }^{1}$ E-mail: suzana.libardi@delmiro.ufal.br

2 E-mail: marit.ursin@ntnu.no
} 
developed by the authors, in three different cities in Brazil, from Northeastern and Southeastern, counting on a total number of 77 adults. They participated through individual and group interviews. The registers of the fieldwork were analyzed and generated categories which deal with the question of who carries the responsibility over children in homeless situation, as well as the protection of marginalized childhood. Based on the empirical work from two researches, we realized that the adults make a differentiation between children who have the streets as their home and those who don't. The participants elected the State as the major responsible for the children in homeless situation. For this marginalized childhood, part of the adults elected governmental institutions as the sole responsible for providing any kind of treatment to the children in homeless situation, which not necessarily means a measure of protection. "Accountability" and "punishment" were much more often mentioned by the adults than "protection". As a conclusion, we saw that the adults have not felt invited to protect marginalized childhood, since they primarily thought about their own protection and even went to a state of neglect towards those children. The acknowledgement of the "pickpockets" was given only by negative means, since the child in homeless situation was seen for some as an evil who acts deliberately, so that this was the only moment when those children were regarded in an active manner.

keywords: children in homeless situation; childhood protection; childhood.

\section{escuchando a los adultos sobre la protección de la infancia y de los niños en situación de calle en el Brasil urbano}

resumen

El presente trabajo se localiza en el área de los estudios de la infancia, que concibe al niño como sujeto activo en la sociedad que está marcado, entre otros factores, por su posición generacional. En esta oportunidad, reflexionamos sobre cómo son percibidos los niños brasileños que viven en el espacio urbano y en un contexto de adversidades muy específico: la calle. El objetivo fue conocer de qué forma los adultos perciben a los niños que se encuentran en situación de calle y cómo ven el deber de protección de la infancia que les corresponde. Con ese fin presentamos los resultados de dos investigaciones cualitativas realizadas separadamente por las autoras de este texto en tres ciudades de Brasil, de las regiones noreste y sudeste, con 77 adultos. Éstos participaron de entrevistas individuales y grupales. Los registros de los trabajos de campo fueron analizados y generaron categorías que contemplan la cuestión de la responsabilidad por los niños en situación de calle y la protección de las infancias marginalizadas. Con base en el trabajo empírico de las dos investigaciones, percibimos que los adultos establecen una amplia diferencia entre los niños que se encuentran en esta situación y los que no tienen la calle como su morada. Los participantes escogieron al Estado como el principal responsable por los niños en situación de calle. Para esa infancia marginalizada nombraron instituciones estatales encargadas de estos niños, pero no necesariamente de su protección. La responsabilización y la punición fueron más evocadas que la protección. Como conclusión, vimos que los adultos no se sintieron convocados a proteger infancias marginalizadas, por eso pensaron de forma prioritaria en su propia protección y rozaron la negligencia con respecto a estos niños. El reconocimiento de los "pivetes" fue realizado exclusivamente por el lado negativo, pues el niño en situación de calle fue visto como un mal que actúa y sabe por qué actúa. Esta situación es la única en que estos niños son percibidos en un papel activo.

palabras clave: niños de la calle; protección de la infancia; infancia. 
escutando os adultos sobre proteção da infância e crianças em situação de rua no brasil urbano

\section{introdução}

A "nova" sociologia da infância buscou colocar atenção sobre as crianças e as infâncias (JAMES; PROUT, 1990; JAMES et al. 1998), reconhecendo a infância como algo passível de ser estudado, sociologicamente, em si e por si mesma (JAMES; PROUT, 1990). Entre outras contribuições, a ênfase desses estudos vem sendo considerar as crianças como atores sociais, que se socializam com sua agência, não sendo sujeitos passivos sob as estruturas sociais. Essas ideias se desenvolveram internacionalmente na paralela ao processo político que gerou a Convenção das Nações Unidas sobre os Direitos da Criança, que reconheceu formalmente as crianças como detentoras de direitos individuais específicos, incluindo direitos de proteção e participação. Esta abordagem para o estudo das crianças e da infância encontrou eco em iniciativas pioneiras que já vinham pesquisando ${ }^{3}$ a infância no Brasil “a partir da ideia da criança como ator social e cultural” (SOUZA, 2015, p. 39), e se expandiu enormemente no país, a partir das décadas de 1980-1990. Atualmente ela não se limita à sociologia, de modo que vem sendo constituída no Brasil a área interdisciplinar dos 'estudos da infância' ou 'estudos sociais da infância' (NASCIMENTO, 2015) - com a qual o presente trabalho visa contribuir.

Quando as crianças passaram a ser reconhecidas como sujeitos específicos de pesquisa, as crianças em situação de rua - ou "crianças de rua", como eram chamadas anteriormente - foram "redescobertas" por pesquisadores acadêmicos. Isso resultou nas décadas seguintes em um aumento impressionantemente rápido na quantidade de publicações sobre crianças em situação de rua (RIZZINI, 1996). O risco de crescer na rua foi amplamente pesquisado e documentado, confirmando o status dos jovens pobres como aqueles que são frequentemente "elementos malvindos" no espaço público (por exemplo SCHEPER-HUGHES; HOFFMAN, 1998; URSIN, 2012, 2016; YOUNG, 2003). Apesar disso, a defesa central da ideia de 
agência das crianças tem influenciado bastante a produção acadêmica, incluindo a referente às crianças que vivem nas ruas. Têm sido reduzidas, por exemplo, as percepções delas como órfãs vulneráveis abandonadas por seus cuidadores; e têm sido mais documentados e reconhecidos pela produção acadêmica o conhecimento prático construído na rua, as capacidades, forças e aptidões desenvolvidas por essas crianças (por exemplo ABEBE, 2008; VAN BLERK, 2005; YOUNG, 2003); incluindo a produção sobre crianças em situação de rua no Brasil (por exemplo BUTLER, 2009; HECHT, 1998; URSIN, 2011).

O presente trabalho se coaduna então com a visão das crianças como sujeitos ativos na sociedade. Considerando, porém, que elas não agem isoladas dos outros grupos de atores sociais, visamos contribuir mais diretamente nessa oportunidade com a discussão de um segundo paradigma colocado pelos estudos da infância: a percepção da infância como grupo geracional, ou seja, das crianças como marcadas, entre outros fatores, pela sua posição geracional perante outras gerações. Por 'geração' nos referimos ao constructo teórico que tenta abarcar as trocas e relações entre sujeitos sociais de mesma faixa etária, a geração como grupo de idade (QVORTRUP, 1985; SARMENTO, 2005); e ao mesmo tempo, geração como grupo de tempo histórico definido, um grupo que compartilha dado momento sociopolítico (ALANEN, 2001). A geração da infância, contudo, não se trata de grupo homogêneo, visto a presença de outras categorias ou marcadores sociais que se imbricam à geração e produzem múltiplas infâncias possíveis. Este trabalho se relaciona a crianças brasileiras que vivem em um contexto de adversidades muito específico: a rua. As crianças em situação de rua são vistas aqui como crianças que - por sua posição geracional e pela questão de classe social, entre outros fatores vivem uma infância marginalizada.

O objetivo desse trabalho foi conhecer de que forma os adultos percebem as crianças que estão em situação de rua, e como veem o dever de proteção da infância aplicado a essas crianças. Os adultos são abordados nesse trabalho enquanto membros de uma geração mais velha que podem ou não ter ligação pessoal com infâncias marginalizadas, tal como são vistas no Brasil as crianças em situação de 
rua. A noção de proteção da infância foi utilizada para convocar os adultos para dentro da discussão sobre geração e relações intergeracionais, visto que a proteção em nossa sociedade é um dever delegado aos mais velhos para com os mais jovens. Com isso, nosso intuito é justamente corroborar com o debate teórico sobre a questão geracional por meio da pesquisa empírica sobre os sentidos que a proteção e o lugar geracional têm (ou não) para os mais velhos no contemporâneo.

\section{proteção da infância e crianças em situação de rua no brasil.}

A proteção da infância vem, ao longo da história do Brasil, adquirindo diferentes contornos. Do início do século XX até os anos 1960, as imagens da infância que vinham, até então, atravessando as ações filantrópicas e estatais eram de: crianças e adolescentes como 'objetos de controle, disciplinamento ${ }^{4}$ e repressão ${ }^{5}$ social' (PINHEIRO, 2006). O discurso filantrópico posicionava crianças pobres como vulneráveis e necessitando de proteção (RIZZINI, 2002). Esse discurso possui duplo significado - já que a infância era tida como período da vida onde as pessoas estão mais inclinadas a desenvolver "maus" hábitos, como "vadiagem" e delinquência (FRAGA FILHO, 1996) - jovens pobres eram reconhecidos como vulneráveis ao perigo, mas também como potencialmente perigosos (RIZZINI, 2002). A solução para o "problema" era o confinamento e a institucionalização (FRAGA FILHO, 1996), já que até esse momento da história do país, a Doutrina da Situação Irregular autorizava o Estado a recluir amplamente "menores" considerados negligenciados, abandonados, órfãos, ou aqueles cujos pais eram desaparecidos, pedintes, declarados incapazes, presidiários, prostitutas, "vagabundos" etc. (RIZZINI, 2002). As práticas de violência nas instituições de reclusão da infância escancaravam o

4 Segundo Pinheiro (2006), as instituições profissionalizantes ligadas à indústria, criadas na década de 1940, encarnaram essa representação dos adolescentes pobres; enquanto que a Legião Brasileira de Assistência, criada em 1942 com apoio de setores da indústrias e comércio (KRAMER, 1982), difundiu essa imagem da criança pobre para basear suas ações, especialmente a do Projeto Casulo, já em 1974.

5 Segundo Pinheiro (2006), os seguintes marcos históricos concretizaram no Brasil essa imagem da criança pobre: o primeiro Código de Menores da América Latina, que entrou em vigor no país em 1927; o Serviço de Atendimento ao Menor, criado em 1940 no Ministério da Justiça, para atender menores abandonados e "delinquentes"; o qual foi substituído em 1964 pela Fundação Nacional para o Bem Estar do Menor (FUNABEM), e suas instituições estaduais, as Fundações Estaduais para o Bem Estar do Menor (FEBEMs). 
interesse governamental de reprimir infâncias marginalizadas (RIZZINI; RIZZINI, 2004); entre elas, as crianças em situação de rua, que estavam completamente subsumidas na imagem do "menor".

A ideia de proteção passava ao largo do atendimento institucionalmente oferecido a essa população. Ela vem sendo disputada por setores específicos da sociedade brasileira, particularmente nas últimas quatro décadas. A partir da década de 1970, o atendimento que vinha sendo ofertado pelo Estado à criança pobre foi sendo fortemente questionado pelos movimentos de defesa dos direitos da criança e do adolescente (PINHEIRO, 2006). Nessa época a luta pelos direitos da criança e do adolescente adquiriu mais força entre alguns grupos organizados da sociedade civil (PINHEIRO, 2006). Difundiu-se a construção social de uma imagem para a criança que refletia as transformações sociais e políticas do país devido ao processo de redemocratização: a imagem da criança e do adolescente como 'sujeitos de direitos' (PINHEIRO, 2006). Intensificaram-se movimentos ${ }^{6}$ que priorizavam a defesa de direitos, denunciando especialmente as situações de negligência, abuso e exploração que afetavam majoritariamente a criança pobre, ao mesmo tempo em que também era buscado o reconhecimento da criança como sujeito social.

A Constituição Federal de 1988 foi, em termos de legislação nacional, um dos mais importantes documentos nesse sentido, pois colocou, ao menos formalmente, as crianças e os adolescentes no centro dos esforços estatais, como objeto de proteção específica7. Seu reconhecimento como ator social foi formalizado apenas mais tarde,

6 Por exemplo: República do Pequeno Vendedor, criada em 1978; Pastoral do Menor, criada em 1978; Movimento de Defesa do Menor criado em 1979; Projeto Alternativas de Atendimento a Meninos de Rua, criado em 1984 pela parceria entre FUNABEM e o Fundo das Nações Unidas para a Infância; Movimento Nacional de Meninos e Meninas de Rua, criado em 1985; Frente Nacional de Defesa dos Direitos da Criança, fundada em 1985; a campanha Criança e Constituinte, do Ministério da Educação, iniciada em 1986; e o Fórum Nacional Permanente de Entidades Não-Governamentais de Defesa dos Direitos da Criança e do Adolescente, fundado em 1988 (PINHEIRO, 2006).

7 Visto que a Constituição de 1988 formalizou: a proteção à infância como um direito social provido pela assistência social - Artigos 203 e 223; o amparo às crianças e adolescentes carentes como um dos objetivos da assistência social - Artigo 223; a assunção legal de crianças, adolescentes e jovens como prioridade do Estado democrático brasileiro e alvo de proteção especial - Artigo 227. Além disso, a proteção especial, oferecida à criança, aparece como respeito à sua condição peculiar de pessoa em desenvolvimento, principalmente quando da aplicação de medidas punitivas ao "menor" - Artigo 227. Há ainda a garantia de outros direitos relativos à saúde, educação, lazer e segurança da criança (BRASIL, 2012). 
com o Estatuto da Criança e do Adolescente, em 1990. No que diz respeito à proteção, na Constituição ainda está presente a ideia de que proteger a infância significa ofertar proteção social para crianças pobres - ou marginalizadas, incluindose as crianças em situação de rua. A ideia de proteção está estritamente ligada à provisão básica, agora vista como um direito, que deve ser ofertado pelo Estado para crianças cujas famílias não podem fazê-lo.

O Estatuto, por sua vez, se refere à criança e ao adolescente, não mais a "menores", e incorpora a obrigação constitucional de família, sociedade e Estado garantirem os direitos dos jovens. No que tange à construção de uma nova imagem para a criança, apesar de ter sido formalmente superada a perspectiva corretivorepressiva, denúncias de abusos policiais no país revelam a persistência da percepção dos jovens pobres como perigosos e ameaçadores à ordem social e econômica (RIZZINI, 2011). Como o Estatuto previu proteção legal das crianças e estabeleceu regras especiais para a privação de liberdade em caso de ato infracional, emergiu uma consequência indesejada da formalização do Estatuto: um aumento de sanções extrajudiciais e homicídios de crianças e adolescentes marginalizados (HECHT, 1998). Este fato, frequente ainda hoje, revela que a imagem da criança como detentora de direitos não é efetivada no Brasil para as infâncias marginalizadas.

No texto do Estatuto, a proteção da criança aparece em diferentes momentos: $1^{\circ}$ ) Proteção ao trabalho ${ }^{8}, 2^{\circ}$ ) Proteção jurídico-social ${ }^{9}$, que deve ser provida à criança com alguma dificuldade no âmbito familiar, ausência de convívio familiar ou crianças que cometeram algum ato infracional; $3^{\circ}$ ) Medidas específicas de proteção ${ }^{10}$, em caso de comprometimento de algum dos direitos da criança; que, de

8 No artigo 60 do Capítulo V, que diz que é a proibição de "qualquer trabalho a menores de quatorze anos de idade, salvo na condição de aprendiz" (BRASIL, 1990, p. 10).

9 Artigos 87 e 90, pelos programas das entidades de atendimento em regime de: "I - orientação e apoio sócio-familiar; II - apoio sócio-educativo em meio aberto; III - colocação familiar; IV - abrigo; V - liberdade assistida; VI - semiliberdade; VII - internação" (BRASIL, 1990, p. 15-16).

10 Artigos 98 e 101. Segundo o último, as medidas específicas de proteção são: “I - encaminhamento aos pais ou responsável, mediante termo de responsabilidade; II - orientação, apoio e acompanhamento temporários; III - matrícula e freqüência obrigatórias em estabelecimento oficial de ensino fundamental; IV - inclusão em programa comunitário ou oficial de auxílio à família, à criança e ao adolescente; $\mathrm{V}$ - requisição de tratamento médico, psicológico ou psiquiátrico, em regime 
acordo com o Artigo 105 do Estatuto, se aplicam também às crianças envolvidas em ato infracional. Ou seja, tais medidas protetivas se aplicam também às crianças, de até doze anos de idade incompletos, que estejam envolvidas ou sejam autoras de crimes ou contravenções penais.

Pelas situações onde a proteção é evocada no Estatuto, percebe-se que a ideia de proteção aparece eminentemente associada a contextos onde se julga carecer algo para a criança ou que se julga que a criança está colocada em situação inadequada para si mesma, como o trabalho. Isso fica evidente quando as medidas específicas de proteção são aplicáveis à criança que já teve algum de seus direitos ameaçados ou violados - demonstrando que a proteção não é compreendida como presente nos contextos "regulares" de desenvolvimento da criança, mas apenas naqueles onde compreende-se que a infância já está sendo violada (ARANTES, 2009) de alguma maneira.

Nossa legislação nacional, seja a Constituição ou o Estatuto, não inseriu a noção de proteção como sendo contemplada nas práticas cotidianas dirigidas à infância como um todo e colocou-a apenas como algo que deve acontecer em situações "de exceção". As crianças em situação de rua são tidas pela legislação como vivendo em situação irregular, e são objeto frequente da proteção estipulada nos termos da lei. A proteção se concretiza até hoje na vida dessas crianças, predominantemente, pelas políticas de assistência social e/ou de segurança pública. Além disso, no que diz respeito a quem provê tal proteção, essa legislação não avançou muito sobre a realidade já colocada, pois as instituições, públicas ou não, que já vinham atuando com infâncias pobres e marginalizadas, continuaram sendo os atores da produção discursiva sobre a proteção destinada à infância. Nesse sentido, a questão geracional - que reconhece a interdependência existente entre gerações (ALANEN, 2001) e aponta para certa reciprocidade entre membros de gerações diferentes (CASTRO, 2013) - não se beneficiou dos avanços na legislação 
nacional. Adentramos o século XXI no Brasil sem que a geração dos adultos fosse provocada a pensar a sua posição diante das infâncias brasileiras.

\section{pesquisando a infância a partir da perspectiva intergeracional: contribuiçãa para os estudos da infância.}

A temática da proteção da infância vem sendo estudada majoritariamente no Brasil considerando o plano macrossocial, por meio por exemplo da análise de políticas públicas e da legislação pertinente (ARANTES, 2009; BARBOSA, 2012; RIZZINI, 2011); ou a partir de instituições que executam declaradamente ações protetivas do Estado sobre a infância/juventude (CFP, 2009; FERNANDES, 2012; MAGALHÃES, 2012; RIZZINI; RIZZINI, 2004). Isso demonstra, a nosso ver, que têm sido focados os serviços de proteção oferecidos institucionalmente às crianças pobres no país, mas nesse processo tem sido pouco estudado como elas são percebidas pelos membros das gerações mais velhas. O presente trabalho, por sua vez, contempla o ponto de vista dos adultos para a discussão sobre proteção e crianças em situação de rua. Tal escolha decorre de razões específicas discutidas a seguir.

No campo dos estudos da infância o reconhecimento das crianças como sujeitos ativos e socialmente competentes (JAMES; PROUT, 1990; JAMES et. al., 1998; STOECKLIN, 2013) gerou a demanda de que as mesmas fossem tratadas como tal não apenas conceitualmente, mas também no próprio processo de pesquisa. Decorreu daí a necessidade de contar com a participação das crianças nas pesquisas sobre elas mesmas e sobre infância de modo geral. Nas últimas décadas, então, "dar voz" ou "ouvir a voz" das crianças se transformou em um procedimento quase hegemônico em estudos da infância (WYNESS, 2013), que migraram da pesquisa sobre para a pesquisa com crianças (CORSARO, 2011).

Segundo Wyness (2013), esse movimento hegemônico, de fazer pesquisa sobre infância com as próprias crianças, partiu da crítica à regulação adulta sobre o agir e a voz das crianças para buscar, então, conhecer sua participação "genuína". Por consequência, segundo o autor, é comum haver certa compreensão de que se obtém mais participação das crianças quando há menos participação dos adultos nos 
contextos onde elas estão atuando; como também é recorrente a equivalência entre empoderamento das crianças e exclusão dos adultos nas experiências de participação delas. Tais equívocos levaram ao que Wyness considera uma "marginalização da perspectiva dos adultos" (WYNESS, 2013, p. 429) e derivou frequentemente de pesquisas baseadas em modelos de participação individualistas e ocidentais - que abafaram outras formas de participação existentes em diferentes contextos culturais onde crianças participam da vida comunitária com os adultos.

Do nosso ponto de vista a contribuição dos estudos da infância, de narrar a infância a partir do lugar das próprias crianças, corrobora para a visibilização desses atores sociais. Contudo, o reconhecimento das crianças nas pesquisas como atores sociais competentes não exclui necessariamente o papel que adultos têm na mediação da experiência de infância, em suas mais diversas expressões. Em que pese a geração adulta ter historicamente dominado as formas de ação e participação da geração da infância (SARMENTO, 2005; WOODHEAD, 1997), as crianças agem em contextos sociais e culturais onde contam majoritariamente com a presença adulta. Além disso, tendo em vista a interdependência característica das relações intergeracionais, é fundamental reconhecer que crianças e adultos, para fazerem valer suas vozes, dependem inexoravelmente da "resposta", da atuação e/ou da escuta do outro.

Também, uma preocupação do revigorado interesse teórico na agência das crianças é, segundo Van Blerk (2012), a falha de reconhecimento das formas pelas quais crianças em situação de rua são conectadas aos outros por meio de relações intergeracionais. Nessa mesma linha, Ansell (2009) problematiza a predominância de estudos empíricos sobre a vida cotidiana das crianças disconectando-a ${ }^{11}$ de processos sociais mais amplos, discursos e instituições. A autora salienta que além de pesquisar com crianças é preciso pesquisar com aqueles que estão ativamente envolvidos em construir as políticas e os discursos que afetam as crianças.

Por essas razões, com o presente trabalho, optamos por conhecer as posições dos adultos a respeito da proteção aplicada à realidade das crianças em situação de

11 Para exceções, ver Swanson (2007) e Ursin (2016). 
rua. A escolha metodológica decorre também da compreensão de que o imperativo da proteção da infância impacta diretamente o papel dos adultos e o papel do Estado na sua relação com as crianças e a infância; pessoas e instituição que são supostamente os provedores da proteção das gerações mais novas. Ademais, parece-nos relevante conhecer a visão de adultos especificamente sobre as infâncias marginalizadas, como as crianças em situação de rua, porque elas vivem uma infância distinta da idealizada - o que diz muito da vida cotidiana dessas crianças, suas relações sociais e encontros na cidade.

\section{as pesquisas realizadas.}

O presente trabalho reúne os resultados de duas pesquisas qualitativas e exploratórias realizadas separadamente pelas autoras, nas cidades de SalvadorBahia - nomeada 'pesquisa 1', Niterói-Rio de Janeiro e Ouro Preto-Minas Gerais - a 'pesquisa 2'. Participaram 77 adultos no total, sendo 34 na pesquisa 1 e 43 na pesquisa 2; com idades entre 18 e 68 anos.

A pesquisa de campo 1 foi realizada dentro de um projeto mais amplo no qual a pesquisadora explorou as perspectivas de experiências com diferentes grupos da sociedade sobre as crianças e adolescentes em situação de rua. Entrevistas estruturadas e com perguntas abertas foram realizadas com: 16 mulheres mães (de 30 a 53 anos de idade) residentes de um bairro pobre, uma favela; e 18 adultos de classe média (de 20 a 68 anos) residentes de um bairro de classe média, o bairro onde foi realizada a etnografia do projeto maior.

As mulheres mães foram contactadas por indicações de uma para a outra em uma favela da cidade e as entrevistas foram conduzidas em suas casas. O critério de seleção foi residir em favela e ser mãe, com a expectativa de obter um melhor entendimento das perspectivas dos pais que têm seus filhos vivendo sob condições socioeconômica e sociocultural similares às de crianças em situação de rua ou têm a mesma origem delas. $\mathrm{Na}$ verdade, alguns dos filhos das participantes tiveram experiências de rua. Os moradores de classe média foram escolhidos pela sua proximidade geográfica dos jovens moradores de rua (do projeto maior), com vistas a entender melhor as atitudes e relações sociais presentes na vida cotidiana de 
crianças e adolescentes em situação de rua. Devido à dificuldade de acesso aos moradores desse bairro, as entrevistas foram conduzidas em três prédios de apartamentos nos quais a pesquisadora tinha residido anteriormente e tinha proximidade com os porteiros. Eles contactaram atuais residentes, e agendaram as entrevistas. As pessoas foram entrevistadas separadamente umas das outras.

A pesquisa 2, por sua vez, contou com grupos de adultos; totalizando 43 participantes, de 18 a 57 anos, sendo 60,46\% mulheres e 39,53\% homens. Ela também foi realizada dentro de projeto maior. A seleção dos participantes considerou como critério a intimidade dos adultos para com o campo da infância - os debates no âmbito dos direitos da criança ou a experiência dos participantes no cuidado ofertado profissionalmente a essa geração. Sendo assim, os participantes foram reunidos de modo a contemplar adultos que trabalham com crianças (no caso, profissionais da educação, que compuseram o grupo A) e adultos que não trabalham com crianças (adultos de várias idades, graduandos de cursos de engenharias e de licenciaturas nas áreas de exatas e ciências naturais, que compuseram o grupo B). O trabalho de campo foi realizado com base na perspectiva dos grupos operativos (BLEGER, 2011; PICHON-RIVIÈRE, 2005). Tal abordagem pareceu ser pertinente para um tratamento não-individual da pesquisa de campo, visto que se reúne as pessoas em torno de uma tarefa concreta (PICHON-RIVIÈRE, 2005) e centramo-as nessa tarefa, por isso tenta-se distinguir as demandas do indivíduo das demandas do grupo para se ater na relação do grupo com a tarefa para a qual ele foi criado. Foi realizado o total de 9 reuniões, separadamente, com os dois grupos de adultos participantes. A tarefa (BLEGER, 2011) colocada para os grupos foi debater o tema da proteção da infância e sua relação com as trocas intergeracionais, considerando especialmente o papel dos adultos nessa provisão. Isso foi feito utilizando-se técnicas que envolviam relatos de histórias pessoais dos participantes e o uso de casos fictícios sobre crianças e suas diferentes infâncias, incluindo o caso de crianças em situação de rua.

A partir das duas pesquisas empíricas realizadas, o presente trabalho traz resultados de estudo com adultos de perfis variados, para que nossa reflexão sobre 
proteção e infâncias marginalizadas não se baseasse apenas no olhar de adultos moradores de favelas ou no olhar de adultos profissionais da área da infância, visto que nosso interesse foi se aproximar um pouco da geração adulta como um todo, contemplando de alguma forma a sua diversidade. Todos os adultos envolvidos foram convidados a participar das pesquisas para debater as relações entre adultos e crianças considerando o tema da proteção e da vida na rua. Contou-se com a participação voluntária de todos eles. Os trabalhos de campo foram registrados com áudio gravado das entrevistas individuais e reuniões grupais, sendo posteriormente transcritos. Relatórios de campo foram elaborados por cada pesquisadora.

escutando os adultos sobre proteção da infância e crianças em situação de rua no brasil urbano.

Os registros dos trabalhos de campo foram analisados conjuntamente e geraram categorias que contemplam a questão de quem é a responsabilidade sobre crianças em situação de rua, e a proteção das infâncias marginalizadas no Brasil, segundo a perspectiva dos adultos. Baseado no trabalho empírico das duas pesquisas, é possível afirmar de maneira geral que os participantes compartilharam uma visão de infância para as infâncias marginalizadas que era distinta das não marginalizadas, de modo que diferenciaram bastante as crianças em situação de rua das outras crianças que não fazem da rua a sua morada. Sobre os posicionamentos dos participantes, não houve diferenças específicas em termos regionais, ou seja, os participantes das pesquisas de campo 1 e 2 não demonstraram compreender diferentemente a proteção em decorrência de variações regionais.

\section{crianças em situação de rua: de quem é a responsabilidade?}

Esta categoria de análise diz de como os adultos participantes da pesquisa veem a questão da responsabilidade sobre infâncias marginalizadas. Ela é relevante porque o cuidado de crianças pobres em situação de rua representa um problema socialmente complexo de lidar e, em uma perspectiva intergeracional, interessounos saber como os mais velhos se posicionam a respeito. 
Quando se discutiu a responsabilidade sobre migração de jovens para as ruas, na pesquisa 1, ocorreu diferença de opinião entre as mães de classe socioeconômica baixa e os moradores de classe média. Enquanto as primeiras frequentemente culparam o comportamento de mães biológicas como as causadoras das crianças viverem na rua, os últimos também perceberam o fenômeno como "problema social" que deveria ter sido manejado pela instância governamental. Entre as mães de classe popular, o papel de mãe como responsável pelo bem-estar e proteção dos filhos foi de importância máxima, enquanto o papel de pai foi raramente mencionado: "Eu penso que as crianças vão para rua porque não encontram apoio da mãe" (mãe, 44 anos); “Tem muitas mães sem responsabilidade e [...] muitas também se envolvem com drogas" (mãe, 39 anos). Nesse sentido, para esse grupo de participantes da pesquisa, a figura materna foi percebida como única responsável pela criança em situação de vulnerabilidade. Além disso, as mães de crianças em situação de rua foram rotuladas como irresponsáveis e disfuncionais; negligenciando o impacto de condições sociais, culturais, econômicas e políticas amplas sobre essas famílias. Apenas duas das mães moradoras de favela relativizaram um pouco a responsabilidade materna sobre essa problemática. Uma delas (de 38 anos) mencionou o governo como responsável de algum modo pela estada das crianças nas ruas, explicitando que "crianças de rua" existem também como consequência do mal tratamento doméstico $e$ da falta de suporte governamental. Outra (de 51 anos) associou o fato à pobreza e à falta de emprego para os pais dessas crianças.

Os moradores do bairro de classe média, em muito maior quantidade, mencionaram ambos os pais como responsáveis, referindo-se aos pais ao invés de às mães. Entre eles, só dois mencionaram os pais como únicos responsáveis, sem se referir à instância governamental de algum modo. Um deles era uma mulher (de 39 anos) que argumentava que mulheres pobres têm filhos para fazê-los de pedintes, e o outro participante, um homem (de 53 anos), disse que "os pais são responsáveis, eles fazem filhos e abandonam". Ambos reconheciam a pobreza na qual as vidas dessas pessoas estão enredadas, mas ainda culpavam em primeiro lugar os pais por terem filhos nessas circunstâncias. 
Os posicionamentos mencionados desses dois últimos participantes foram exceção. A grande maioria dos adultos de classe média associou a falha dos pais no cuidado adequado de seus filhos às causas estruturais de pobreza, inequidade social, falta de escolarização de qualidade e empregos. Tal qual uma das participantes (mulher, de 25 anos) argumentou:

"A criança tá na rua porque os pais botam. Os jovens usam drogas. Os adultos vendem coisas ou moram sem outras oportunidades. Alguns roubam. Tem aqueles que preferem pedir dinheiro do que trabalhar, usando droga. [É por cause de] desigualdade social, pobreza, falta de oportunidade, e educação".

Similarmente, outra mulher (de 33 anos) disse que os "pais não cuidam. Fome, falta de emprego". O governo foi muito mais responsabilizado, por crianças estarem em situação de rua, entre os participantes de classe média do que entre os de classe pobre, como é exemplificado por uma das participantes (de 25 anos), argumentando que algumas crianças estão nas ruas devido à "falta da educação dos pais. Necessidade. Culpa é dos pais e do governo, por que ninguém queria estar na rua". Uma das adultas de classe média participante da pesquisa era diretora da associação de moradores daquele bairro e ela, entre outros participantes, falou explicitamente sobre abandono parental $e$ governamental. Esse resultado se aproxima de outro estudo realizado entre a elite brasileira. Na pesquisa de Reis (2005), pessoas dessa classe socioeconômica rejeitaram sugestões de que pessoas pobres são responsáveis por sua condição, e os perceberam como vítimas da inequidade social, da não ação de governantes e de políticas inadequadas.

Enquanto nenhuma das mães de classe socioeconômica popular mencionou a era colonial brasileira e a história de escravidão, ambas foram indicadas como causas estruturais por três homens da classe média entrevistados. Um deles (de 31 anos) explicou as razões para crianças viverem nas ruas:

"[É devido a] história da colônia. De repente liberaram todos os escravos. Isso era um momento chave, e o impacto era que você não é mais escravo, então vai para rua. Os ricos continuam bem, os negros não. [...] O nível cultural e de educação do baiano é muito baixo por causa da abolição de escravidão. [...] 90\% da população da rua é raça negra. Deveriam ter ficado na África".

Sua declaração não só culpa as raízes históricas da escravidão, mas também contém um discurso de inferioridade racial dos afro-brasileiros, questionando o direito deles de pertencimento no Brasil. Os outros dois homens, que também se 
referiram à história colonial do país como uma problemática, destacaram principalmente a desigual distribuição de poder e capital que permanece desde então: "vem do tempo colonial. As políticas mal feitas e concentração de renda" (homem, 29 anos).

"É uma questão cultural. Abandono mesmo. Eles que têm poder não ligam. Eles estão bem dentro dos carrose apartamentos deles. [Tem algo a ver com] corrupção também" (homem, 25 anos).

Como dito acima, políticos e pessoas com poder político estão sendo responsabilizados pela injustiça social e desigualdade econômica, que deixa crianças e famílias vulneráveis, e torna a vida nas ruas uma opção viável. Novamente, tal resultado faz eco a Reis (2005) pois, em sua pesquisa, a elite responsabilizou o período colonial pela inequidade persistente no país. $\mathrm{O}$ impressionante é que, segundo Reis, raramente as pessoas questionam como esse legado tem persistido e por quê. Na pesquisa 1 nenhum dos entrevistados de classe média percebeu sua própria classe socioeconômica como responsável pela continuada inequidade socioeconômica do país. Isso foi percebido mais e primeiro como algo externo às suas próprias vidas e para além da capacidade deles de mudança enquanto cidadãos.

Resultados semelhantes também apareceram na pesquisa 2. Alguns dos participantes evocaram o Estado como um dos responsáveis pela presença de crianças nas ruas, sua atividade de pedir dinheiro e/ou possível envolvimento em atividades ilícitas. Segundo eles, o Estado é falho e "não investe em educação e nem em lugares para acolher essas crianças", disse Matilde ${ }^{12}$, integrante do grupo B. Outros falaram da negligência do Estado como justificativa para o fato de crianças roubarem, por exemplo. "Isso que a gente [outros participantes] discutiu aqui: o que seria 'o certo' e o que é na realidade, entendeu? Então, se o governo cumprisse seu papel.... teria solução!", disse Fabíola, também do grupo B. Considerando as duas pesquisas realizadas, a maioria dos participantes elegeu o Estado como o maior responsável pelas crianças em situação de rua, já que os resultados da pesquisa 2 se somam aos posicionamentos dos moradores de classe média da pesquisa 1. De acordo com Reis

12 Todos os nomes utilizados para identificar os participantes da pesquisa 2 são fictícios com vistas a preservar a identidade dos participantes. A utilização de nomes fictícios foi autorizada pelos participantes da pesquisa. 
(2005), a elite se retrata ao Estado por evitar assumir qualquer compromisso social para com a pobreza. Assim, ela pode se eximir da geração de mudança social, o que pode também ter sido o caso dos participantes de nossas pesquisas.

No que tange à responsabilidade sobre essas crianças, um último assunto evocado por ambos os grupos da pesquisa 1 - moradores de classe média e mães de classe pobre - foi o planejamento familiar e controle de natalidade. Novamente, houve distinção nas diferentes formas de explicar como esse planejamento é responsável pela falta de controle em termos de natalidade na população pobre: enquanto as mães de classe socioeconômica baixa culpam unicamente as mulheres por terem crianças sem ter meios para cuidar delas; a maioria dos moradores de classe média, por sua vez, argumentou que a falta de planejamento familiar entre a população pobre era também responsabilidade governamental. Esse resultado é exemplificado por uma mãe (de 45 anos) que argumentou que "é a falta de planejamento familiar. As pessoas têm muitos filhos e não conseguem cuidar deles"; e outra (de 40 anos) indicou que "as famílias têm que ter mais estruturas e isso [crianças de situação de rua] não é uma culpa do governo". Mulheres pobres tendo crianças também foi visto como algo indesejável e problemático por residentes de classe média, mas eles viram isso principalmente como responsabilidade do governo de controlar esse "problema". Tal qual uma mulher (de 36 anos) disse:

"As pobres parem, parem, parem. Não têm comida em casa, e as crianças vão para rua e fazem crimes. Estou a favor a ligar [as trompas]. O governo perguntar às mulheres quantos filhos têm. Três basta".

Mães de estrato socioeconômico baixo são, dessa forma, vistas como promíscuas ou ignorantes, e em necessidade de controle estatal invasivo sobre sua saúde reprodutiva e formação familiar. Segundo Barroso e Bruschini (1991 apud CARDAELLO, 2012) essa 'cultura da esterilização' de mulheres pobres no Brasil advém, entre outras razões, de programas internacionais efetivados aqui que difundiam a crença de que a causa da pobreza era o grande número de crianças gestadas pela classe economicamente pobre, e consequentemente, o julgamento da conduta das mulheres pobres como irresponsáveis.

Outra entrevistada (de 31 anos) argumentou nessa linha: 
"Tem muito falta de planejamento familiar. Deveria ter controle de natalidade. A mulher pobre deveria ter educação e assistência familiar. Deveria ter limite de máximo dois filhos. Deveriam distribuir remédios, informação, fazer vasectomia e a mulher usar DIU. Criar uma lei punitiva igual à China. Tem que ser radical, porque as mulheres estão se engravidando para ganhar a Bolsa Família".

Pelo trecho recortado da entrevista, foi desenhado uma relação direta entre mulheres pobres, seus filhos e futuras "doenças sociais", como jovens rondando as ruas e se engajando em atividades delinquentes. Além disso, essas mães foram percebidas como manipuladoras, por "tirarem vantagem" de um sistema de benefício social, ou como mencionado acima, explorando as crianças enquanto pedintes.

Tal compreensão e culpabilização da população pobre, em especial das mulheres pobres, também ocorreu entre adultos integrantes da pesquisa 2. Boa parte deles indicou o Conselho Tutelar como autoridade competente para lidar com essa população. O grupo das adultas que trabalham com crianças, as professoras, foi o que mais lembrou do Conselho. Mencionaram que a denúncia poderia ser anônima para proteger a identidade do denunciante. Elas discutiram também o papel das mães dessas crianças. O descrédito para com tais mães demonstrou que nem todos os adultos são vistos de maneira legítima para se responsabilizarem por crianças. No caso específico, por mais que houvesse o vínculo parental, tido como algo relevante pelos grupos participantes da pesquisa, eles não o reconheceram com a importância devida. Nesse sentido, a retirada do poder e da autonomia das mães pobres sobre seus filhos, que tem ocorrido frequentemente por parte do Estado, não pareceu incomodar a maioria dos adultos de ambas as pesquisas realizadas.

\section{a proteção das infâncias marginalizadas a partir da perspectiva dos adultos.}

Esta categoria de análise aborda diretamente a ideia de proteção da infância, sob o ponto de vista dos adultos participantes da pesquisa 2. Foi possível promover uma discussão coletiva, entre os participantes de cada um dos grupos envolvidos na investigação, por meio do uso de casos fictícios (LIBARDI, 2016). As histórias fizeram os participantes pensar e se posicionar sobre qual ação (protetiva? institucional? pessoal?) julgavam adequada para se lidar com crianças em situação 
de rua no contexto da cidade - permitindo, assim, conhecermos (se havia) alguma noção de proteção subjacente aos seus discursos.

Diante de infâncias marginalizadas, o movimento mais forte dos participantes foi evitar que adultos "comuns", que não têm ligação pessoal com essas crianças, agissem de forma direta sobre a problemática; com "suas próprias mãos". Uma parte dos participantes defendeu que adultos "em geral", como eles, não devem se envolver de forma alguma com os problemas enfrentados por crianças que vivem nas ruas. "Ah, pera aí! Ela [a adulta "comum", personagem da história fictícia em debate na atividade grupal] já tem um monte de problema. Ela ia passar reto e ia falar: 'Porra, que pena. Sorte que não é o meu filho!'”, disse David, integrante do grupo B. A primeira postura a ser adotada por eles seria ignorar a situação vulnerável em que muitas vezes se encontram crianças nas ruas e não agir para a proteção delas porque "a gente tem medo de se envolver, porque a gente quer ajudar, mas a gente fica assim... com medo", disse uma das professoras do grupo A. Segundo algumas participantes desse e do outro grupo, o adulto até gostaria de agir e fazer algo nesse tipo de situação, mas isso implica um risco e esse risco inibe ou bloqueia a ação direta. Relatos semelhantes ocorreram na pesquisa 1 por participantes da classe média, como por exemplo: "Sinto pena e medo e receio. De ajudar e de ele [menino em situação de rua] fazer algo mal" (mulher, de 38 anos).

Apenas uma das participantes da pesquisa 2 argumentou contra a ideia de que se deve ignorar os acontecimentos na rua envolvendo "pivetes". Uma das participantes argumentou que, independente das consequências, a criança precisa de uma ação imediata porque, no caso da história fictícia em análise, está sofrendo violência. "Ele é um pivete, tudo bem, mas é um ser humano, tá sendo espancado", disse Matilde, integrante do grupo B. Eles não reconheceram a ideia de 'direitos humanos' como algo relevante e que impõe algum apelo à ação adulta perante violações que o menino da história estava sofrendo. Segundo Matilde, apesar de a criança em questão ser um "pivete" - criança que comete pequenos crimes, ou uma 'criança em conflito com a lei' - resta-lhe ainda a condição intrínseca de ser humano; o que já seria razão suficiente para alguém prover alguma ajuda. Além disso, chamou atenção o fato de nenhum participante ter evocado nesse momento os direitos 
especiais da criança e sua condição diferenciada perante a lei, também enquanto apelos para o comprometimento adulto. Esses argumentos praticamente não ecoaram entre os adultos para fazê-los agir para com a criança - demonstrando a complexidade do debate e a pouca mobilização para com essa infância. Houve também quem justificasse a não-ação por avaliar que realmente não cabe a eles agir. Uma das participantes do grupo de adultos que não trabalha com crianças fez várias falas para defender esse argumento. Segue uma:

\begin{abstract}
"Véi, tipo, ela [a adulta "comum", personagem da história] tá indo pro trabalho, saca? Pode parecer egoísmo, pode parecer o que for. Isso não compete a ela, saca? Isso não compete a civis. O menino não tá na escola. Já era pra ele estar na escola. [...] O que você vai fazer? Colocar todo mundo dentro da sua casa? Você não vai fazer isso jamais. Isso é um problema social, isso não é um problema, tipo, civil, individual. Compete muito mais à galera que tá lá em cima no poder, tipo, projetar socialmente mesmo, pra botar esse povo pra aprender um trabalho, do que a gente mesmo" (Conceição, integrante do grupo B).
\end{abstract}

Na fala transcrita defende-se o distanciamento da esfera pública por parte dos indivíduos e a responsabilização dos governantes como aqueles que concentram toda a obrigação de resolver a problemática das crianças que vivem nas ruas das cidades. Há, porém, um entendimento equivocado do que venha a ser a vida civil, visto que ela aparece como equivalente apenas ao âmbito individual da experiência dos cidadãos, descartando a participação na esfera pública como uma parte também integrante da vida civil. Tal perspectiva reflete a desconexão que a participante fez entre si mesma, enquanto cidadã, e os problemas macrossociais - o que também foi percebido entre adultos de classe média da pesquisa 1. Um posicionamento que não gerou grandes discordâncias no grupo de adultos onde ocorreu, os quais concordaram com a avaliação principal de que problemas envolvendo meninos em situação de rua não dizem respeito a todos os cidadãos, de algum modo. Uma perspectiva que, infelizmente, condiz hoje com a opinião de parte da sociedade brasileira sobre vida civil, espaço público e infância.

"[...] Esses meninos aí, que tão na rua, não têm nada a perder. Pra eles não é difícil se juntar e meter uma facada na barriga dela [a adulta "comum" que está observando] e sair correndo. E eu acho que eles não pensariam nem duas vezes em se vingar dela, caso ela denunciasse" (Conceição, integrante do grupo B).

No trecho transcrito, denota-se a não empatia total de alguns adultos pelas crianças em situação de rua e pelas infâncias marginalizadas em nossa sociedade. 
As crianças em análise também são vistas como despossuídas de qualquer coisa relevante em suas vidas, uma visão preconceituosa que alimenta a imagem violenta e sem valor atribuída a essa infância.

Diante de situações onde tais crianças encontram-se em apuros (exemplos: estão sofrendo violência por alguém ou "levando uma dura" da polícia), outra opção indicada pelos participantes seria chamar a polícia. "A gente vê direto, na nossa frente, do outro lado da rua, a gente ignora. Aí no máximo ela [a adulta "comum" que está observando] falaria pra polícia" disse David, integrante do grupo B. "[...] A atitude melhor ali daquele momento é denunciar e aguardar a polícia chegar. Então é melhor avisar a polícia e esperar pra ver o que eles fazem", disse uma das integrantes do grupo A. Participantes dos dois grupos da pesquisa 2, adultos que trabalham ou não com crianças, indicaram que ligariam para a polícia. Entre as "saídas" possíveis, a polícia levaria o menino para uma "instituição de menores". Isso ilustra o destino frequente da infância "de rua" no Brasil: envolvimento com algum tipo de delito e posterior institucionalização. Um destino que reflete nossa história de institucionalização de crianças pobres e demonstra o quanto ela ainda está viva no imaginário da população, que delega facilmente essa infância às leis punitivas e ao Estado livrando o adulto comum de qualquer envolvimento.

A institucionalização de crianças em situação de rua também pode ser observada na fala a seguir:

"[...] Ela deveria procurar as autoridades, a polícia e tal, pra poder... pra conseguir... solucionar o problema. Não se meter no meio da briga [o espancamento do menino], mas chamar um policial pra poder apartar lá e conseguir... prender o garoto, conseguir... resolver a situação" (Peter, integrante do grupo B).

Pela transcrição, a polícia aparece como autoridade competente para resolver o problema. A prisão da criança aparece como solução. Além disso, a "briga" à qual se referiu o participante não foi relatada como tal no caso fictício, mas sim um espancamento de uma criança por adultos. Ao falar em "briga", minimiza-se a ação de violência sobre o "pivete". O papel adulto, até aqui, seria ignorar o caso ou repassar a criança em situação de rua à polícia, mesmo que isso custasse sua institucionalização. Considerando que a polícia também, frequentemente, continua os abusos e violências cometidos contra "pivetes", o que fazer? "A gente pensou em 
chamar a polícia porque o pertinente à polícia é solucionar esses problemas, não a gente, entendeu?", disse Andrés, do grupo B, tentando se justificar em seguida com o argumentou de que o mau tratamento dado pela polícia já dizia respeito a um "outro problema". Segundo ele, isso já era uma questão pela qual não podem ser responsabilizados, por mais que eles tivessem chamado essa polícia. Ao repassarem o caso para a autoridade policial, negaram as consequências desse ato sobre a criança. Assim, chamariam a polícia para intervir, mesmo reconhecendo que não resolveria adequadamente a situação.

Os adultos falaram também como veem as instituições de recolhimento dessas crianças. Um dos participantes disse que a criança, nesse caso:

\footnotetext{
"Vai pra alguma instituição, que não é cadeia, pra tentar corrigir o comportamento. Eu não sei qual é a idade, mas tem até uma certa idade, não sei se é 13 ou 15, que se a criança cometer algum desses crimes, seja lá qual for, se for até mesmo um homicídio, ela é tida como incapaz. Aí, tu não pode prender. Ela é como um incapaz, né? Fez sem saber o que tava fazendo. Mas é complicado isso de 'incapaz'. Veja aquele caso [descreveu caso de assassinato cometido por uma criança]. Naquele caso, o policial pegou [a criança] $e$ soltou. Ele [o menino autor do crime] foi dado como incapaz. Não deu em nada. E aí pô, revoltante, né?" (David, integrante do grupo B).
}

$\mathrm{O}$ trecho transcrito se refere à problemática da maioridade penal do Brasil, ou seja, a condição de 'incapaz' da criança e a forma que ela é tratada, na prática, no país. A condição peculiar da criança na legislação brasileira não foi vista aqui como uma forma de protegê-la, mas sim como uma forma de deixar impune o crime cometido por ela. Na fala, o participante não contempla as medidas socioeducativas previstas na legislação nacional, e mostra a maneira negligente e errada pela qual a polícia vem encaminhando frequentemente tais casos. No grupo B, de adultos que não trabalham com crianças, a maioria dos participantes avaliou que "pivetes" não são devidamente punidos hoje, especialmente porque não reconhecem na legislação nacional ferramenta adequadamente colocada em prática, ou porque, de fato, transpareceu aceitar a violência física como punição possível.

Adultos de classe média da pesquisa 1 argumentaram na mesma linha:

"A lei é deficiente. Sou contra proteção do menor. O menor tem que pagar igual um adulto. Com 16 anos votam, decidem o futuro do país. Eles têm que responder o que faz. Até 14 anos. Não acredito em recuperação nem no FEBEM. Porque conheço vários que não melhorou, mas piorou" (mulher, 31 anos). 
De modo geral, então, nossas pesquisas revelam que o papel do adulto foi sobretudo de punir, sendo conivente com a autoridade policial, por exemplo. A punição da infância marginalizada e em conflito com a lei aparece completamente ligada ao castigo físico. A legislação a respeito é tida como ineficaz pelos adultos. A criança em situação de rua foi concebida como um agente que faz coisas erradas; e essa imagem da criança não evocou nos adultos atitudes protetoras. A ideia de proteção da infância foi inexistente para crianças que causam "o mal". Nesses casos, os adultos demonstraram se preocupar mais consigo próprios.

\section{conclusões}

Os participantes de nossas pesquisas, em geral, partiram do pressuposto de que adultos "comuns" não devem se envolver em problemas enfrentados por crianças em situação de rua ou, caso haja algum envolvimento, devem fazê-lo de forma indireta e cuidando para não gerar consequências ruins para si mesmos. Vimos que os adultos não se sentiram convocados a proteger infâncias marginalizadas, por isso pensaram prioritariamente em sua própria proteção e beiraram a negligência para com essas crianças. A imensa maioria dos participantes elencou instituições estatais como as únicas responsáveis por prover algum trato às crianças em situação de rua; o qual não necessariamente se configurou como uma medida de proteção para infância marginalizada.

Em termos de conclusão, enxergamos nas duas pesquisas realizadas alguns resultados mais gerais a respeito do papel dos adultos, enquanto geração, para com crianças em situação de rua no Brasil - uma infância que desafia a lei, pois tais crianças cometem delitos, criam formas de enfrentar as adversidades do espaço urbano, são "safos" e marginalizados. Considerando os resultados encontrados, avaliamos, por um lado, que os "pivetes" vivem duplamente um não reconhecimento da sua condição: o não reconhecimento do seu status de criança, do seu "tipo" de infância, e também o não reconhecimento como pessoa portadora de direitos. Por outro lado, essas crianças foram reconhecidas pelos adultos por vias negativas, já que foram vistas como um "mal" que age e sabe por que age. Tal reconhecimento gerou como consequências responsabilização e punição. Esse movimento não está descolado da conjuntura atual 
do Brasil e se soma aos retrocessos ocorridos na democracia brasileira, haja vista as tentativas de redução da maioridade penal no país em 2015 e 2017.

O fator geracional não foi evocado em momento algum, nos discursos dos adultos envolvidos no presente trabalho, como algo motivador à ação protetiva de crianças em situação de rua. Eles perceberam majoritariamente a proteção como responsabilidade governamental, e não como algo possível de envolvê-los enquanto adultos e cidadãos. A partir daí, conclui-se que os participantes das pesquisas não endossaram a visão mais tradicional de que necessariamente, na relação entre adultos e crianças, eles protegem elas. Os adultos mostraram com seus posicionamentos que a proteção dependente muito da relação em análise, pois a proteção será provida ou não na relação.

Os trabalhos de campo demonstraram que a proteção da infância não representou para os adultos uma base normativa para todos eles perante todas as crianças; revelando que a proteção não é um valor para as trocas intergeracionais, mas apenas para algumas trocas intergeracionais. Apesar da geração dos adultos ser mais experiente, apesar de ela ter a "função" de apresentar esse mundo às crianças, e de inseri-las nesse mundo, ela não foi vista como minimamente convocada a agir em prol das infâncias de alguma forma, mas apenas em prol de determinadas crianças. A posição geracional não foi apelo suficiente para adultos protegerem crianças em situação de rua.

\section{referências}

ABEBE, T. Earning a living on the margins: Begging, street work and the socio-spatial experiences of children in ABABA, A. Geografiska Annaler: Series B, Human Geography, v. 90, n. 3, p. 271-284, 2008.

ABRAMOWICZ, A. Estudos da infância no Brasil: encontros e memórias. São Carlos, SP: EDUFSCar, 2015.

ALANEN, L. Explorations in generational analysis. In: ALANEN, L.; MAYALL, B. (Orgs.). Conceptualizing child-adult relations. London, New York: Routledge, 2001. p. 11-22.

ANSELL, N. Childhood and the politics of scale: descaling children's geographies? Progress in human geography, v. 33, n. 2, p. 190-209, 2009.

ARANTES, E. M. de M. Proteção integral à criança e ao adolescente: proteção versus autonomia? Psic. Clin., v. 21, n. 2, p. 431 - 450, 2009.

BARBOSA, M. Sobre mães e filhos: as políticas públicas de proteção à maternidade e à infância em Guarapuava (1940 a 1960). 2012. 158 f. Dissertação (Mestrado acadêmico em História)- Universidade Federal do Paraná, Curitiba, 2012. 
BLEGER, J. Temas de psicologia: entrevistas e grupos. São Paulo: WMF, Martins Fontes, 2011. BRASIL. Lei no 8.069, de 13 de julho de 1990, Estatuto da Criança e do Adolescente. Brasília: Presidência da República, 1990.

BRASIL. Constituição da República Federativa do Brasil: Texto constitucional promulgado em 5 de outubro de 1988, com as alterações adotadas pelas Emendas Constitucionais n¹/1992 a 68/2011 pelo Decreto Legislativo ${ }^{\circ} 186 / 2008$ e pelas Emendas Constitucionais de Revisão n 1 a 6/1994. Brasília: Câmara dos Deputados, Edições Câmara, 2012.

BUTLER, U. Freedom, revolt and 'citizenship': Three pillars of identity for youngsters living on the streets of Rio de Janeiro. Childhood, v. 16, n. 1, p. 11-29, 2009.

CARDARELLO, A. The right to have a family: 'legal trafficking of children', adoption and birth control in Brazil. Anthropology \& Medicine, v. 19, n. 2, p. 225-240, 2012.

CASTRO, L. R. de. O futuro da infância: os impasses nas relações intergeracionais e das crianças com seus pares. In: CASTRO, L. R. de. O futuro da infância e outros escritos. Rio de Janeiro: 7Letras, 2013. p. 37-84.

CFP (CONSELHO FEDERAL DE PSICOLOGIA). Serviço de Proteção Social a Crianças e Adolescentes Vítimas de Violência, Abuso e Exploração Sexual e suas Famílias: referências para a atuação do psicólogo. Brasília, 2009.

CORSARO, W. A. Sociologia da Infância. Porto Alegre: ArtMed, 2011.

FERNANDES, A. P. P. Enfermeiro na identificação das potencialidades e fragilidades do trabalho em rede de proteção contra a violência na infância. 2012. 135 f. Dissertação (Mestrado acadêmico em Enfermagem)- Universidade Federal do Paraná, Curitiba, 2012.

FRAGA FILHO, W. Mendigos, Moleques e Vadios na Bahia do Século XIX. São Paulo: HUCITEC/EDUFBa, 1996.

HECHT, T. At home in the street. Cambridge: Cambridge University, 1998.

JAMES, A.; PROUT, A. Constructing and reconstructing childhood. London: Falmer Press, 1990.

JAMES, A. et. al. Theorizing Childhood. Cambridge: Polity Press, 1998.

KRAMER, S. História do atendimento à criança brasileira. In: KRAMER, S. A Política do Préescolar no Brasil: a arte do disfarce. Rio de Janeiro: Achiamé, 1982. p. 49-91.

LIBARDI, S. S. A proteção da infância e as relações intergeracionais a partir da perspectiva dos adultos. 2016. 266 f. Tese (Doutorado em Psicologia)- Instituto de Psicologia, Universidade Federal do Rio de Janeiro, Rio de Janeiro, 2016.

MAGALHÃES, K. C. O devir-criança como potência na invenção de novos possíveis no encontro entre a psicologia, a justiça e a infância. 2012. 156 f. Dissertação (Mestrado acadêmico em Psicologia)- Universidade Federal do Rio de Janeiro, Rio de Janeiro, 2012.

NASCIMENTO, M. L. B. P. Como de conduz a pesquisa da infância quando a educação é mais um campo a compor seus estudos? Alguns elementos para discussão. Currículo sem Fronteiras. v. 15, n. 1, p. 79-93, jan./abr. 2015.

PICHON-RIVIĖRE, E. O processo grupal. São Paulo: Martins Fontes, 2005.

PINHEIRO, A. Criança e adolescentes no Brasil: porque o abismo entre a lei e a realidade. Fortaleza: Universidade Federal do Ceará, 2006.

QUINTEIRO, J. Sobre a emergência de uma Sociologia da Infância: contribuições para o debate. Perspectiva, Florianópolis. v. 20, n. especial, p. 137-162, jul./dez. 2002.

QVORTRUP, J. Placing children in the division of labour. In: CLOSE, P.; COLLINS, R. (Orgs.). Family and economy in modern society. Hong Kong: Macmillan Press, 1985. p. 129-145. REIS, E. Perceptions of poverty and inequality among Brazilian elites. In: REIS, E.; MOORE, M. (Eds.). Elite perceptions of poverty and inequality. London: Zed books, 2005. p. 26-56.

RIZZINI, I. Street children: An excluded generation in Latin America. Childhood. v. 3, n. 2, p. 215-233. 1996. 
RIZZINI, I. The Child Saving Movement in Brazil. Ideology in the Late Nineteenth and Early Twentieth Centuries. In: HECHT, T. (Ed.). Children in Latin American History and Society. Madison: University of Wisconsin, 2002. p. 165-180.

RIZZINI, I. Crianças e menores: do pátrio poder ao pátrio dever. Um histórico da legislação para a infância no Brasil. In: RIZZINI, I.; PILOTTI, F. (Orgs.). A arte de governar crianças: a história das políticas sociais, da legislação e da assistência à infância no Brasil. São Paulo: Cortez, 2011. p. 97-150.

RIZZINI, I.; RIZZINI, I. A institucionalização de crianças no Brasil: percurso histórico e desafios do presente. Rio de Janeiro: Ed. PUC-Rio; São Paulo: Loyola, 2004.

SARMENTO, M. J. Gerações e alteridade: interrogações a partir da sociologia da infância. Educação e Sociedade, v. 26, n. 91, p. 361-378, maio/ago. 2005.

SCHEPER-HUGHES, N.; HOFFMAN, D. Brazilian apartheid: Street kids and the struggle for urban space. In: SCHEPER-HUGHES, N.; SARGENT, C. (Eds.). Small wars. Berkeley: University of California, 1998. p. 352-388.

SOUZA, M. L. A. de. Abordagens conceituais da criança e da infância: sociologia, antropologia e educação. In: SOUZA, M. L. A. de."Ser quilombola": identidade, território e educação na cultura infantil. 2015. 265 f. Tese (Doutorado em Educação) - Universidade Estadual de Campinas, Campinas, SP, 2015. p. 32-65.

STOECKLIN, D. Theories of action in the field of child participation: In search of explicit frameworks, Childhood, v. 20, n. 4, p. 443-457. 2013.

SWANSON, K. Revanchist urbanism heads south: The regulation of indigenous beggars and street vendors in Ecuador. Antipode, v. 39, n. 4, p. 708-728. 2007.

URSIN, M. 'Wherever I lay my head is home' - Young people's experience of home in the Brazilian street environment. Children's Geographies, v. 9, n. 2, p. 221-234. 2011.

URSIN, M. 'The city is ours': The temporal construction of dominance among poor young men on the street in a Brazilian elite neighborhood. Journal of Latin American Studies, v. 44, n. 3, p. 467-493. 2012.

URSIN, M. Contradictory and Intersecting Patterns of Inclusion and Exclusion of Street Youth in Salvador, Brazil. Social Inclusion, v. 4, n. 4, p. 39-50. 2016.

VAN BLERK, L. Negotiating spatial identities: Mobile perspectives on street life in Uganda. Children's Geographies, v. 3, n. 1, p. 5-21. 2005.

VAN BLERK, L. Berg-en-See street boys: Merging street and family relations in Cape Town, South Africa. Children's Geographies, v. 10, n. 3, p. 321-336. 2012.

WOODHEAD, M. Psychology and the cultural construction of children's needs. In: JAMES, A.; PROUT, A. (Eds.). Constructing and Reconstructing childhood: contemporary issues in the sociological study of childhood. London: Falmer Press, 1997. p. 63-84.

WYNESS, M. Children's participation and intergenerational dialogue: bringing adults back into the analysis. Childhood, v. 20, n. 4, p. 429-442. 2013.

YOUNG, L. The 'place' of street children in Kampala, Uganda: marginalisation, resistance, and acceptance in the urban environment. Environment and planning D: Society and space. $\mathrm{v}$. 21, n. 5, p. 607-627. 2003.

recebido em: 27.09 .2017

aceito em: 12.11.2017 